\title{
Oral acyclovir in the management of dendritic herpetic corneal ulceration
}

\author{
S. O. HUNG, ' A. PATTERSON, ${ }^{1}$ D. I. CLARK, ${ }^{1}$ AND P. J. REES ${ }^{2}$ \\ From 'St Paul's Eye Hospital, Liverpool and the ${ }^{2}$ Wellcome Research Laboratories, Beckenham, Kent
}

SUMMARY ' A controlled trial of oral acyclovir in herpetic dendritic corneal ulcers was carried out on 31 patients. All patients received minimal wiping debridement of the ulcer, following which they were randomly allocated to receive either oral acyclovir or placebo for 7 days. At the end of treatment $67 \%$ of dendritic ulcers in patients receiving acyclovir had healed compared with $43 \%$ in placebo recipients. The proportion of ulcers healed in the 2 groups at 7 days showed no significant difference $(p=0 \cdot 18)$, but the rate of healing was significantly faster in the acyclovir group $(p=0 \cdot 03)$.

Acyclovir is a potent antiviral agent with selective activity against virus infected cells. Many studies have shown that topical acyclovir is effective in the management of superficial dendritic ulceration of the cornea. ${ }^{1-9}$ Satisfactory plasma and aqueous levels can be achieved following oral administration of acyclovir without toxic systemic effects. ${ }^{10-13}$ There is evidence that systemic therapy with intravenous acyclovir is effective in the treatment of severe herpetic keratitis. ${ }^{14}$ This preliminary study is designed to determine whether oral acyclovir has any therapeutic activity in herpes simplex dendritic corneal ulceration in a randomised placebo-controlled trial in which either oral acyclovir or placebo was given after a minimal wiping debridement of the ulcer, which can cure about $50 \%$ of dendritic ulcers. ${ }^{15}$

\section{Materials and methods}

Patients who presented in the casualty department of St Paul's Eye Hospital, Liverpool, with a superficial dendritic herpetic ulcer and had given their informed consent were included. Patients excluded were those who had deep stromal disease, were unable to attend regularly for assessment, had received steroid therapy within the last 2 months, had received antiviral therapy within the last month, were women of child bearing potential, or had poor visual acuity in the other eye. Patients were examined by slit lamp after staining the cornea with rose Bengal. All patients received minimal wipe debridement with cotton tipped swab at the slit lamp. ${ }^{16}$ They were then

Correspondence to: Mr S. O. Hung, St Paul's Eye Hospital, Old Hall Street, Liverpool L3 9PF. randomly assigned to oral acyclovir $400 \mathrm{mg}$ or placebo 5 times daily for 7 days. The patients were seen on alternate days and examined by slit lamp microscopy and the ulcer stained with rose Bengal to assess healing or recrudescence. Patients were immediately withdrawn from the trial if there was evidence of recrudescence or recurrence and given topical antiviral therapy. Patients were reviewed 3 months after the end of the trial. All patients included were assessed as healed or failed on day 7 .

\section{Results}

Thirtyone patients were included in this study. Two patients were excluded from the analysis because no clinical assessment was made on day 6,7 , or 8 . Fourteen patients received placebo and 15 patients received acyclovir tablets. The groups were compared for age, ulcer size, duration and severity of symptoms, and severity of stromal disease and uveitis (Table 1)

Table 1 Patients' characteristics at presentation

\begin{tabular}{llll}
\hline & & Placebo & Acyclovir \\
\hline Sex & Male & 10 & 13 \\
& Female & 4 & 2 \\
Age (years) & Median & 61 & 51 \\
Ulcer type & Large & 7 & 6 \\
& Small & 5 & 5 \\
Ulcer size (mm) & Multiple & 2 & 4 \\
Duration of symptoms (days) & Median & $2 \cdot 5$ & $2 \cdot 7$ \\
Severity of symptoms (score) & Median & 6 & 5 \\
Stromal disease (score) & Mean & $1 \cdot 5$ & $1 \cdot 4$ \\
Uveitis (score) & Mean & $0 \cdot 9$ & $0 \cdot 5$ \\
& Mean & $0 \cdot 5$ & $0 \cdot 5$ \\
\hline
\end{tabular}


Table 2 Clinical response

\begin{tabular}{lll}
\hline & Placebo & Acyclovir \\
\hline Percentage healed & $43 \%$ & $67 \%$ \\
Days to dealing (median) & $>8$ & 7 \\
\hline
\end{tabular}

by Mann-Whitney U tests. Proportions of each sex and ulcer type were compared by $\chi^{2}$ tests. No differences were found between the groups at the $5 \%$ level of significance. $67 \%$ of dendritic ulcers healed within 7 days following oral acyclovir, and $43 \%$ of dendritic ulcers healed in those treated with placebo (Table 2). The proportion of dendritic ulcers healed in the 2 groups were compared by Fisher's exact test. No significant difference was found $(1$-tailed $p=0 \cdot 18)$. However, the acyclovir group healed significantly faster $(\log$ rank analysis, 1 -tailed $p=0 \cdot 03$, Fig. 1).

All ulcers that failed to heal were treated with topical idoxuridine. No adverse reaction was found in the acyclovir treated group.

\section{Discussion}

Most recurrences of dendritic ulcers occur within 7 days after minimal wiping debridement. ${ }^{15}$ Therefore, dendritic ulcers that failed to heal in 7 days should be regarded as recrudescent. $43 \%$ of ulcers in patients treated with minimal wipe debridement and placebo healed. This result is similar to those of other studies, ${ }^{15-17}$ and it shows no significant difference from the healing rate of $67 \%$ in the acyclovir treated group. If oral acyclovir has a therapeutic effect on dendritic ulceration, one would expect a higher healing rate in the acyclovir group.

There can be 2 possible reasons for the healing rate of only $67 \%$ in the acyclovir treated group. The first is

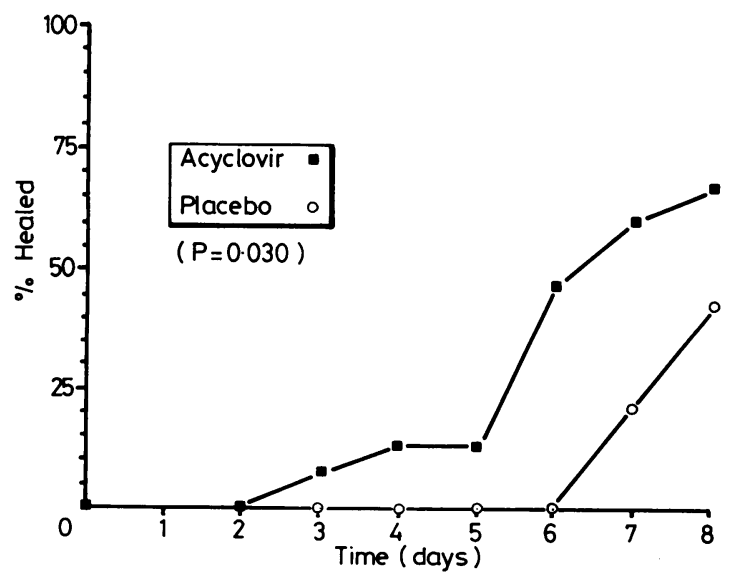

Fig. 1 Healing time of dendritic ulcers. that the minimal wiping debridement was improperly carried out. Consequently the debridement was insufficient to remove all infected epithelium. This reason is unlikely, as the result of $43 \%$ healing rate in the placebo treated group is comparable with that in other studies. The second reason is that there may be an inadequate level of acyclovir in the tears, which may be important in the treatment of superficial corneal ulceration. Studies have been carried out to determine the plasma and aqueous levels of acyclovir following oral administration. Levels well in excess of the in vitro $\mathrm{ED}_{50} \mathrm{~S}$ for herpes simplex virus type 1 and type 2 were found, ${ }^{10-13}$ and indeed acyclovir has been used systemically in advanced herpetic corneal disease with good response,${ }^{14}$ but no data are yet available on the levels of acyclovir achieved in tear fluid.

Oral administration will inevitably lead to some delay in achieving therapeutic levels of acyclovir in ocular tissues. This delay may have allowed virus replication to continue for some time following minimal wiping debridement and may explain the healing rate of only $67 \%$ at 7 days. A longer course of oral therapy may be required.

Topical acyclovir provides immediate therapeutic levels in the area of infection and has been shown to offer complete protection against recrudescences following minimal wiping debridement. ${ }^{17}$ While the efficacy of oral acyclovir in the management of superficial herpetic keratitis must remain in question, further studies with a longer duration of therapy may be justified, since oral therapy may be more acceptable to those patients who are unwilling or unable to comply with frequent applications of ophthalmic ointment.

\section{References}

1 Jones BR, Coster DJ, Fison PN. et al. Efficacy of acycloguanosine (Wellcome 248U) against herpes simplex corneal ulcers. Lancet 1979; i: 243-4.

2 Coster DJ, Wilhelmus KR, Michaud R, Jones BR. A comparison of acyclovir and idoxuridine as treatment for ulcerative herpetic keratitis. Br J Ophthalmol 1980; 64: 763-5.

3 McCulley JP, Binder PS, Kaufman HE. et al. A double blind, multicenter clinical trial of acyclovir vs idoxuridine for treatment of epithelial herpes simplex keratitis. Ophthalmology 1982; 89: 1195-200.

4 Laibson PR, Pavan-Langston D, Yeakley AR, Lass J. Acyclovir and vidarabine for the treatment of herpes simplex keratitis. $A m$ J Med 1982; 73: 281-5.

5 Collum LMT, Benedict-Smith A, Hillary I. Randomised doubleblind trial of acyclovir and idoxuridine in dendritic corneal ulceration. Br J Ophthalmol 1980; 64: 766-9.

6 Colin J, Tounoux A, Chastel C, Renard G. Superficial herpes simplex keratitis. Double blind comparative trial of acyclovir and idoxuridine. Nouv Presse Med 1981; 10: 2969-75.

7 Klauber A, Ottovay E. Acyclovir and idoxuridine treatment of herpes simplex keratitis-a double blind clinical study. Acta Ophthalmol (Kbh) 1982; 60: 838-44. 
8 McGill J, Tormey P, Walker CB. Comparative trial of acyclovir and adenine arabinoside in the treatment of herpes simplex corneal ulcers. Br J Ophthalmol 1981; 65: 610-3.

9 Young BJ, Patterson A, Ravenscroft T. A randomised double blind clinical trial of acyclovir (Zovirax) and adenine arabinoside in herpes simplex corneal ulceration. Br J Ophthalmol 1982; 66: 361-3.

10 Brigden D, Fowle A, Rosling A. Acyclovir, a new antiherpetic drug: early experience in man with systemically administered drug. In: Collier LH, Oxford J. eds. Developments in antiviral therapy. London: Academic Press, 1980: 53-62.

11 Van Dyke RB, Straube R, Large K, et al. Pharmacokinetics of increased dose oral acyclovir. 22nd Interscience Conference. Antimicrob Agents Chemother 1982; 139: abstr 414.

12 De Miranda P, Whitely RJ, Barton N, et al. Systemic absorption and pharmacokinetics of acyclovir (ACV) (Zovirax) capsules in immunocompromised patients with herpes virus infections. 22nd Interscience Conference. Antimicrob Agents Chemother 1982; 139: abstr 418

13 Hung SO, Patterson A, Rees PJ. Aqueous levels of acyclovir following oral administration. 2nd international acyclovir symposium. Br J Ophthalmol in press.

14 Van der Meer JWM, Versteeg J. Acyclovir in severe herpes virus infections. Am J Med 1982; 73(1A): 271-4.

15 Jones BR, Coster DJ, Falcon MG. Topical therapy of ulcerative herpetic keratitis with human interferon. Lancet 1976; ii: 128.

16 Jones BR, Coster DJ, Falcon MG, Centell K. Clinical trials of topical interferon therapy of ulcerative viral keratitis. J Infect Dis 976; 133 (suppl 6): A169-72.

17 Jones BR, Coster DJ, Fison PN, et al. Efficacy of acycloguanosine (Wellcome 248U) against herpes simplex corneal ulcers. Lancet 1979 ; i: $243-4$. 